\title{
ESTRATÉGIAS DE FOMENTO INSTITUCIONAL PARA OFERTA DE CURSOS A DISTÂNCIA NA EXTENSÃO DA UNICAMP
}

CAMPINAS/SP JULHO/2018

\author{
EDILENE APARECIDA ROPOLI - UNICAMP - edilene@unicamp.br \\ GLÁUCIA BEATRIZ DE FREITAS LORENZETTI - UNICAMP - glaucia@extecamp.unicamp.br \\ PEDRO EMERSON DE CARVALHO - UNICAMP - pedro@extecamp.unicamp.br
}

Tipo: Relato de Experiência Inovadora (EI)

Categoria: Estratégias e Políticas

Setor Educacional: EDUCAÇÃO CONTINUADA EM GERAL

\begin{abstract}
RESUMO
Uma das primeiras iniciativas em educação a distância na Universidade Estadual de Campinas foi em 1997, com o lançamento do AVA TelEduc, um ambiente virtual de aprendizagem. Desde então, tem havido várias iniciativas para discutir e estimular o EAD na Universidade por meio de sucessivos Grupos de Trabalho. A área de extensão tem sido a mais expressiva na oferta de cursos a distância. Em 2016 lançou um Edital de chamada para apresentação de projetos de desenvolvimento e oferecimento de cursos de extensão em EAD para fomentar a oferta desses cursos com o uso das Tecnologias Digitais de Informação e Comunicação, disponibilizando recursos financeiros e apoio institucional. Este artigo faz um breve relato histórico do EAD na Unicamp e uma análise dos resultados deste Edital, a partir dos relatórios de atividades apresentados pelos coordenadores dos cursos. Foram analisadas informações qualitativas dos relatórios e depoimentos dos coordenadores de sete dos doze cursos contemplados no edital, visando sistematizar as práticas, ressaltar aspectos positivos das experiências e possibilidades de melhorias, contribuindo na definição de estratégias futuras para a oferta de novos cursos na modalidade a distância na Unicamp. Algumas mudanças a serem consideradas na elaboração de futuros editais são: valorizar critérios que possibilitem atingir maior número de pessoas, como número de alunos, abrangência do público alvo e possibilidade de oferecimento de várias turmas do curso; avaliação da qualidade dos materiais produzidos, em especial das videoaulas; reformulação o processo de avaliação do curso pelos alunos, para que de fato possam apontar onde as intervenções são necessárias, permitindo melhor gerenciamento dos cursos oferecidos. Para promover o aumento do número de docentes interessados em atuar em EAD é essencial que a Universidade instrumentalize os docentes e mantenha uma política de fomento para novas iniciativas, até gerar autonomia na produção e oferta de cursos em EAD.
\end{abstract}

Palavras-chave: EDUCAÇÃO A DISTÂNCIA, EXTENSÃO, FOMENTO PARA EAD, GESTÃO EM EAD

AGRADECIMENTOS

AGRADECIMENTOS À UNICAMP PELO PATROCÍNIO DOS CURSOS DE EXTENSÃO; À EXTECAMP PELA ORGANIZAÇÃO E GESTÃO; AO GGTE PELO APOIO AO USO DAS TECNOLOGIAS; E À EDUCORP, PELO APOIO FINANCEIRO. 


\section{INTRODUÇÃO}

Uma das primeiras iniciativas em educação a distância (EAD) na Universidade Estadual de Campinas (UNICAMP) data de 1997, quando o Núcleo de Informática Aplicada à Educação (NIED) lançou a primeira versão de um ambiente virtual de aprendizagem (AVA), denominado TelEduc. Em 1999 a UNICAMP criou o 10 Grupo de Trabalho em EAD (GTEAD) com objetivos de fazer um balanço sobre EAD na Unicamp e propor soluções para seu desenvolvimento. Para isso fez uma consulta à comunidade acadêmica sobre o uso de tecnologias na educação; criou uma infraestrutura vinculada ao Centro de Computação da Unicamp (CCUEC) e contratou pessoas com perfis específicos para atuarem no órgão criado.

O 10 GTEAD propôs algumas recomendações, entre as quais se destacam: desenvolver um projeto abrangente de EAD, com visão estratégica unificada, contemplando as condições necessárias para que se torne atividade significativa e efetiva em todos os âmbitos de ensino; estimular a apoiar os docentes que quiserem se aprofundar em EAD; articular ações entre a Coordenadoria Geral da Universidade (CGU), pró-reitorias e diretorias de unidades; criar uma Comissão Assessora em Educação a Distância, ligada à CGU, para fomentar, assessorar e facilitar as atividades em EAD; criar um curso interdisciplinar para formação de docentes em EAD.

Com o objetivo de apoiar e dar suporte às iniciativas de EAD na Universidade, no ano de 2000 foi criada a Equipe de Apoio a EAD - CCUEC, de caráter multidisciplinar, e foram adquiridos equipamentos e software para dar suporte às ações de EAD da Universidade. Ainda neste ano foi criado o 2o GTEAD e em 2002 o 30 GTEAD, com objetivos de coordenar, supervisionar e acompanhar as atividades de EAD na Unicamp e identificar as iniciativas isoladas de EAD desenvolvidas em diversas unidades de ensino.

Em 2002 foi dado um grande passo em relação às disciplinas de graduação com a criação do Ensino Aberto (EA), um ambiente que integrava as informações da Diretoria Acadêmica (DAC) ao AVA TelEduc. A integração consistia na abertura de áreas para todas as disciplinas de graduação com atualização dos respectivos coordenadores, professores e alunos.

Em 2004 a EAD começa integrar o Planejamento Estratégico da Universidade (PLANES), com objetivo de incentivar/consolidar ações de EAD, facilitar o acesso às informações e aos materiais didáticos e fornecer o apoio técnico e operacional para a implantação dessas atividades com o uso de Tecnologias Digitais de Informação e Comunicação (TDIC). 
Dentro desta perspectiva, a equipe de EAD passou a divulgar assuntos relacionados a EAD por meio de um site; oferecer cursos de formação e tutoriais sobre metodologias e ferramentas de EAD para a comunidade acadêmica; manter as listas EAD-L e EAD-Links; promover encontros de usuários do EA TelEduc para troca de experiências; além de continuar com a oferta de consultoria e atendimento aos usuários; auxiliar na elaboração de projetos pedagógicos para cursos nas modalidades semi-presencial e a distância; dar suporte técnico relacionado aos AVAs, tecnologias multimídia, videoconferências, transmissão via Web, entre outros.

Neste período, outras ações de fomento à EAD surgiram na Universidade. Por exemplo, em 2006 foi criada a Comissão de Ensino à Distância (CEaD) da Faculdade de Ciências Médicas (FCM), responsável por coordenar, promover, estimular, assessorar e oferecer recursos humanos e materiais para o desenvolvimento de projetos, que resultou na criação do grupo de Suporte Didático e Divulgação Técnico Científica. Ainda em 2006 a Faculdade de Educação ofereceu um curso de Formação de Gestores da rede de ensino do Estado de São Paulo, na modalidade semi-presencial, atendendo 6.000 Gestores, o que propiciou experiência e apropriação de recursos tecnológicos na perspectiva de ensino e aprendizagem.

Em 2007 foi criado o Conselho de Tecnologia da Informação e Comunicação (ConTIC), órgão responsável pelas políticas e diretrizes na área de TIC, o qual recomendou a criação de um Comitê Permanente para Assuntos de EAD com os objetivos de levantar problemas, discutir soluções e elaborar propostas de políticas e estratégias para EAD na Unicamp, que serviriam de base para a tomada de decisões da Reitoria e Pró-Reitorias ligadas ao ensino.

Para isso foi criado o $4^{\circ}$ GTEAD com objetivos de levantar informações sobre a infraestrutura existente e as atividades de EAD que estavam sendo realizadas e propor uma política de EAD para a Unicamp. Este GT recomendou a criação de uma coordenadoria com a missão de apoiar, articular e promover atividades relacionadas ao uso de TICs na educação, o que resultou na criação do Grupo Gestor de Educação a Distância (GGEAD) em 2008. Os objetivos deste grupo era propiciar, apoiar, articular e promover ações institucionais relacionadas ao desenvolvimento de EAD nos níveis de graduação, pós-graduação e extensão, além de atuar como interlocutor da Universidade junto a outras instituições a fim de identificar oportunidades de parcerias para implantação de cursos a distância e contribuir para políticas públicas no setor. Dentre as ações realizadas destacam-se o credenciamento junto ao MEC para oferta de cursos de Pós-Graduação Lato Sensu a distância; Workshop "EAD na Unicamp" e participação em diversos fóruns organizados por alunos e docentes para discutir as questões 
relacionadas com EAD na Unicamp e seu papel com relação à UNIVESP, o que acabou não se viabilizando por uma forte resistência da comunidade acadêmica.

Ainda no ano de 2008 o PLANES UNICAMP ratifica os objetivos do PLANES 2006 e em 2009 formaliza o Grupo Gestor de Tecnologias na Educação (GGTE), vinculado à PRG e PRPG, reforçando os objetivos do GGEAD definidos em 2008. Este grupo tinha como meta desenvolver as seguintes ações: divulgar o uso do EA por meio de capacitação de docentes e alunos do Programa de Estágio Docente (PED); promover o desenvolvimento do Open Courseware; definir um processo de publicação de materiais e de licenciamento de conteúdos; disponibilizar estrutura de apoio e facilitar as iniciativas em EAD; discutir e encaminhar propostas e projetos; mediar negociações para a utilização de polos de ensino; auxiliar na elaboração de convênios e contratos; auxiliar os docentes na implantação das TDICs. Convém ressaltar que neste período o GGTE atuou no curso semipresencial de Especialização Lato Sensu do Programa Rede São Paulo de Formação Docente (RedeFor), formando 4.050 professores entre 2010 a 2012 e 8.000 professores entre 2012 e 2013.

Paralelamente às atividades do GGTE, outras atividades foram sendo realizadas por diversos outros órgãos da Universidade, sendo a EXTECAMP um dos locais mais expressivos na oferta de cursos a distância, uma vez que seu próprio regimento permite esta modalidade de ensino. Em 2013 foi lançada a primeira iniciativa de um Curso Online Aberto e Massivo, do inglês Massive Open Online Course (MOOC), pela UNICAMP, por meio da iniciativa da Faculdade de Engenharia Elétrica e de Computação, utilizando uma plataforma própria desenvolvida para este fim. Em 2014 foi estabelecida a parceria entre UNICAMP e COURSERA para produção de MOOCs, que resultou no lançamento de quatro cursos em 2015, seguido de outras iniciativas nos anos seguintes.

Em 2016 o AVA Moodle foi incorporado ao EA, ampliando o acesso para as disciplinas de pós-graduação. Em 2017, em parceria com a GOOGLE, foi disponibilizado o AVA CLASSROOM para todas disciplinas e anunciada a desativação do AVA EA-TelEduc devido às dificuldades de atualização da plataforma para incorporar novas tecnologias. Com essas mudanças, o GGTE amplia suas atividades de treinamento para facilitar a apropriação dos novos ambientes pela comunidade acadêmica. Neste mesmo ano a UNICAMP, por intermédio da Pró-Reitoria de Extensão e Assuntos Comunitários (PREAC)-EXTECAMP e apoio da CGU, lançou o Edital PREAC-EAD 01/2016 para apresentação de projetos para desenvolvimento e oferecimento de Cursos de Extensão em EAD (UNICAMP, 2016). O objetivo do edital foi fomentar iniciativas de oferta de cursos de extensão a distância com o uso intensivo das TDICs, disponibilizando 
recursos financeiros e apoio institucional. O desenvolvimento dos cursos deveria ocorrer em seis meses após a divulgação dos resultados do edital e o início do primeiro oferecimento deveria ocorrer ao longo do segundo semestre de 2017.

\section{OBJETIVO}

O objetivo deste artigo é, a partir dos relatórios finais elaborados e entregues pelos coordenadores dos cursos que foram desenvolvidos e oferecidos por meio do Edital PREAC-EAD 01/2016, fazer uma análise qualitativa sob o ponto de vista dos coordenadores visando sistematizar as práticas que poderão contribuir na definição de estratégias futuras, ressaltando os aspectos positivos das experiências e apontando o que precisa ser melhorado, de tal forma que contribua com novas ofertas de cursos na modalidade a distância da Universidade.

\section{REFERENCIAL TEÓRICO}

A formação e o incentivo aos docentes para o uso de TDIC na educação, em especial dos AVAs, é um processo que requer várias ações. Isso se torna mais necessário nas Instituições de Ensino Superior públicas, uma vez que o ensino na modalidade presencial tem obtido bons resultados e as resistências ao uso de TDICs no ensino ainda são recorrentes. FREEMAN (2003) diz que é necessário entender as razões que levam os docentes a terem uma idéia negativa da adoção de TDICs. O autor afirma que as resistências às mudanças são naturais e que são justificadas por diversas razões, tais como insegurança, perda do aspecto social, perda econômica, perda do controle, receio do desconhecido, perda de influência e receio de informações incompletas.

Certamente a mudança de cultura perpassa pelo planejamento estratégico das instituições, envolvendo gestores e equipes multidisciplinares de profissionais comprometidos com formação, suporte, infra-estrutura, recursos humanos e materiais, tendo em vista um modelo de desenvolvimento de cursos oferecidos na modalidade a distância. Neste sentido, segundo LEVY (2003 apud ARAÚJO et al. 2013), é "essencial que gestores, docentes e técnicos administrativos e operacionais envolvidos na implementação da EAD, passem a entender e aceitar a declaração da visão da Instituição e se mostrem dispostos a assumir suas implicações e colaborar no processo de mudança, que envolve os aspectos físicos, tecnológicos, organizacionais, culturais e programáticos da Instituição. Dessa forma, a fase de planejamento e o desenvolvimento de políticas institucionais para cursos online são a chave para um programa de aprendizagem eficiente". 
Tão importante quanto o planejamento estratégico da instituição - e inerente a ele - é a questão de garantir meios para que a EAD ocorra. Segundo BATES (2016), "A adoção da aprendizagem híbrida e online requer um padrão muito mais elevado de formação para os docentes e instrutores. Não se trata apenas de uma questão de aprender a usar o ambiente virtual (...) o uso da tecnologia precisa ser combinado em uma compreensão de como os alunos aprendem, como as habilidades são desenvolvidas, como o conhecimento é representado por meio de diferentes mídias". Assim, oferecer meios de viabilizar experiências em EAD e investir na formação dos docentes são fundamentais para a inserção de TDICs no processo de ensino e aprendizagem e possibilitar o desenvolvimento e a oferta de cursos em EAD nas Instituições, de forma a ampliar e diversificar as experiências que, uma vez sistematizadas, possam contribuir para a definição do planejamento estratégico da Instituição acerca do tema.

\section{PROCEDIMENTOS METODOLÓGICOS}

A metodologia do presente artigo utiliza um breve relato histórico temporal do EAD na Unicamp, bem como a análise qualitativa de cursos EAD contemplados em Edital interno.Neste edital foram submetidos 33 projetos, dos quais, considerando a verba disponibilizada pela Universidade e os valores solicitados pelos coordenadores, foram selecionados doze projetos. Destes doze projetos foram entregues, até presente data, sete relatórios, que serão objeto de análise deste trabalho. A análise se baseará nas informações qualitativas a partir dos relatórios e depoimentos dos coordenadores.

\section{APRESENTAÇÃO E DISCUSSÃO DOS RESULTADOS}

As análises qualitativas serão feitas a partir dos relatórios apresentados pelos coordenadores dos cursos entregues ao final da primeira oferta. Para este trabalho apresentamos as características comuns aos cursos na Tabela 01 e as especificidades de cada curso, identificados de C01 a C07. 


\begin{tabular}{|c|c|c|c|c|c|c|c|}
\hline Cursos $\gg$ & $\mathrm{C} 01$ & $\mathrm{C} 02$ & $\mathrm{C} 03$ & $\mathrm{C} 04$ & $\mathrm{C} 05$ & $\mathrm{C} 06$ & $\mathrm{C} 07$ \\
\hline AVA & Coursera & Moodle & Moodle & Moodle & Moodle & Moodle & Moodle \\
\hline Qclade Hores & 40 & 48 & 32 & 120 & 180 & 30 & 30 \\
\hline Grátis & $\operatorname{sim}^{*}$ & กão & não** & não & não & $\operatorname{sim}$ & não \\
\hline Inscritos & 1.111 & 10 & 13 & 42 & 33 & 83 & 13 \\
\hline Ativos & 724 & & & & & & \\
\hline Concluintes & 69 & 9 & 10 & 28 & Em andamento & 29 & 10 \\
\hline Certificados & 59 & 9 & 10 & 28 & Em andamento & 29 & 10 \\
\hline Desistentes & & 1 & 3 & 14 & & 2 & \\
\hline Reprovados & & & & & & 52 & 3 \\
\hline
\end{tabular}

* pagamento de uma taxa caso o estudante queira o certificado de conclusão

** distribuição de bolsas integrais e parciais

Tabela 01 - Características comuns aos cursos oferecidos

O Curso C01, disponibilizou o conteúdo por meio de vídeos, sugestões de leituras e testes que contabilizam a nota final. Para o desenvolvimento do curso foi contratado um monitor de pós-graduação para preparar material didático a partir do conteúdo programático definido pela equipe de docentes e para auxiliar no logística da produção dos vídeos, que foi feita por uma empresa terceirizada. $\mathrm{Na}$ etapa de oferecimento do curso, um monitor ficou disponível para responder às dúvidas dos estudantes e acompanhar os indicadores disponíveis na plataforma. A avaliação dos estudantes na plataforma Coursera foi predominantemente positiva. Dos 32 estudantes que fizeram a avaliação, 91\% deram a nota máxima ao curso, comentando sobre a boa qualidade dos materiais, a fácil navegação na plataforma e excelente didática dos docentes.

O Curso C02 disponibizou o material didático por meio de videoaulas, glossário, roteiros de aulas práticas, textos em PDF, questionários e exercícios práticos sobre o conteúdo. A avaliação foi baseada em exercícios de múltipla escolha ao final de cada tópico. Para interação foram usados os fóruns de discussão e realizadas quatro videoconferências pelo sistema BigBlueButton (BBB) integrado à plataforma Moodle. Os docentes avaliaram como positiva a interação por meio das videoconferências, pois estreitaram relações entre professor-aluno e estimularam o interesse e a participação dos estudantes nas atividades. Em relação às dificuldades encontradas, foi necessário rever a organização dos conteúdos, pois inicialmente foi projetado para disponibilizar os temas semanalmente e, frente à complexidade do conteúdo e do tempo necessário para realização das atividades, foi alterado para quinzenal.

O Curso C03 disponibilizou o material didático do curso por meio de videoaulas e 
webconferências. O coordenador relatou a dificuldade com a produção dos vídeos, que inicialmente ficou na responsabilidade da Coordenadoria de Desenvolvimento Cultural (CDC) da Unicamp. Também apontou a necessidade de aumentar o número de inscritos por meio de uma divulgação mais direcionada, um ajuste no valor do curso e oferecer mais bolsas, tendo em consideração o perfil do público alvo.

O Curso C04 disponibilizou um manual com as informações necessárias para bom aproveitamento do curso e com as orientações das ferramentas do AVA utilizadas. Fez uso do fórum denominado "Café" para confraternização social e networking entre os estudantes. Para cada aula foi aberto um fórum para discussão e entrega dos trabalhos coletivos e foi disponibilizado material referente aos conteúdos das videoaulas e links para outros materiais e tutoriais. Um fórum para tirar dúvidas ficou permanentemente aberto durante o curso. Também foram realizadas videoconferências quinzenais usando o BBB entre docentes e alunos e entre os próprios alunos para realizar os trabalhos coletivos. Além do Moodle e do BBB, foram usados recursos do Google Forms e e-mail para encaminhar dúvidas técnicas. O coordenador relatou alguns problemas: dificuldades técnicas com os sistemas da Extecamp e com a configuração do Moodle; alunos que abandonaram o curso por dificuldades de ingresso à plataforma; falta de conhecimento sobre regras e normas administrativas da Extecamp; perda de bolsista com experiência em EAD, tendo que cancelar a produção de alguns materiais inicialmente previstos.

O relatório cita, como pontos fortes, a relevância da proposta e facilidade de transpor o conteúdo para o contexto profissional, a qualidade dos materiais, do apoio didático e técnico-administrativo e a proximidade entre os alunos e os docentes do curso. Como pontos a serem revistos, cita os problemas como o ritmo acelerado do curso, a dificuldade de realizar trabalhos em grupo a distância, a falta de praticidade dos fóruns como espaço de trabalho coletivo, a heterogeneidade dos estudantes e a falta de familiarização com os software utilizados. Foram apontados, também, os benefícios aos bolsistas que trabalharam no curso, tais como a experiência de trabalho em equipe multidisciplinar, oportunidade de usar a experiência em suas pesquisas, participar de um curso em EAD, conhecer as necessidades do público-alvo e refletir sobre o design dos AVAs a partir da interação humano-máquina.

O Curso C05 disponibilizou o material didático por meio de videoaulas, complementadas com texto e artigos para leitura. Foram aplicados questionários sobre 0 conteúdo e imagens para descrição dos achados histológicos e/ou clínicos. As videoaulas e os feedbacks em vídeo foram produzidos pela área de suporte da FCM. A digitação de lâminas para compor o acervo do curso foi terceirizada e a coordenação 
relatou a dificuldade de encontrar empresas que oferecem esses serviços.

O Curso C06 disponibilizou o material didático por meio de videoaulas, materiais de leitura e atividades. Foi ressaltado que a interação mais utilizada pelos alunos, tanto para tirar dúvidas sobre a plataforma quanto do conteúdo do curso, foi por meio de mensagens, embora tendo fóruns disponíveis no AVA para este fim e a wiki, que foi pouco usada pelos estudantes. Entre as dificuldades apontadas destaca-se os problemas de acessibilidade no site da Extecamp para alunos com deficiência visual, causando dificuldades para os alunos que dependeram de uma pessoa vidente para realizar a inscrição. O mesmo ocorreu com o Moodle, cujos recursos escolhidos para disponibilizar alguns conteúdos apresentaram problemas de acessibilidade, sendo necessário criar estratégias para garantir a participação de todos. Isso se tornou um problema pois o curso era justamente sobre Tecnologias Assistivas. De acordo com o relatório, o curso cumpriu o objetivo proposto e instrumentalizou os interessados no uso da tecnologia proposta.

O Curso C07 ofereceu o material didático em videoaulas, textos digitalizados, animações, atividades gamificadas, entre outros. A produção de vídeos de animação foi feita com empresa terceirizada e a produção das videoaulas foi feita por meio de parceria entre Extecamp e Rádio e Televisão Unicamp (RTV). O relatório apresentado não traz informações sobre os aspectos positivos e/ou dificuldades vivenciadas durante o processo de desenvolvimento e oferta do curso.

\section{CONSIDERAÇÕES FINAIS}

Editais desta natureza são extremamente necessários para proporcionar a apropriação do conhecimento dos docentes e discentes da Universidade e incentivar a oferta de outros cursos a distância a partir das experiências adquiridas. Os dados estatísticos a partir de 2001 - especificamente da Extecamp - mostram que a EAD surge muito timidamente e que a partir de 2016 e 2017 houve um aumento significativo da oferta de cursos a distância, via MOOCS e via AVA - MOODLE. Em 2013 foram oferecidos 4 cursos a distância, sendo um deles um MOOC. Em 2014 foram oferecidas 4 turmas via MOOC do mesmo curso lançado em 2013, que se repetiu em mais 2 turmas em 2015, juntamente com mais seis novos cursos via MOOC, já na plataforma Coursera, totalizando 8 cursos via MOOCs e dois em AVAs. Este incremento na oferta dos MOOCS está diretamente relacionado a outras formas de fomento que destinaram recursos financeiros para essas iniciativas. Em 2016 foi dada a continuidade de seis cursos via MOOC do ano anterior e ofertados quatro novos cursos, totalizando dez MOOC e oito cursos em AVA. Em 2017 totalizaram 11 cursos via MOOC, sendo dez do ano anterior que deram prosseguimento e um curso novo financiado pelo edital, além de 
18 cursos em AVAs, sendo dez deles financiados pelo edital, objeto deste artigo. Esses números mostram que o interesse dos docentes em atuar na modalidade a distância tem crescido significativamente nos últimos anos e para isso é essencial que a Universidade mantenha uma política de fomento para que mais iniciativas possam ser contempladas, até gerar autonomia na produção e oferta de cursos de extensão em EAD.

A análise dos relatórios produzidos pelos coordenadores dos cursos também resultaram em algumas mudanças que serão consideradas na elaboração de futuros editais. Um deles é tornar o critério de número de alunos / abrangência como um item relevante na seleção dos projetos, bem como a possibilidade de reprodutibilidade do curso, com o oferecimento de novas turmas, de tal forma que os cursos oferecidos possam atingir um maior número de pessoas. Outro item está vinculado à produção dos materiais, em especial às videoaulas. Foram utilizados recursos da própria Universidade (CDC, RTV, FCM) e também foram terceirizados. Convém novos estudos para avaliar a qualidade dos materiais produzidos e sugerir algumas normas e procedimentos para elaboração de vídeos institucionais. Por fim, as avaliações dos cursos realizadas pelos alunos mostraram-se insuficientes, segundo os coordenadores, para uma análise efetiva da opinião dos alunos e possíveis melhorias, demonstrando uma necessidade do processo de avaliação além da apliacação de uma escala Likert. Esse instrumento de avaliação necessita ser reformulado para trazer elementos que de fato possam contribuir com a avaliação dos cursos e fazer intervenções onde se mostrar necessário, permitindo melhor gerenciamento dos cursos oferecidos.

\section{REFERÊNCIAS}

ARAÚJO, E. M. et al. A gestão da inovação na educação a distância. Gestão \& Produção (UFSCAR. Impresso), v. 20, n. 3, p. 639-651, 2013.

BATES, A. W. T. Educar na Era Digital: design, ensino e aprendizagem. São Paulo: Artesanato Educacional, 2016 (Coleção Tecnologia Educacional).

FREEMAN, R. Planejamento de sistemas de educação à distância: Um manual para decisores. The Commonwealth of Learning (COL). Vancouver, Canadá, 2003. Disponível em: <http://www.abed.org.br/col/planejamentosistemas.pdf>. Acesso em: 10/03/2018.

LIKERT, R. (1932). "A Technique for the Measurement of Attitudes". Archives of Psychology 140: 1-55.

UNICAMP. Edital PREAC-EAD 01/2016 - Chamada para Seleção de Projetos para desenvolvimento e oferecimento de cursos de extensão a distância. Disponível em 